\title{
CONSUMPTION TREND OF OPIOIDS IN AMBULATORY PATIENTS IN ALBANIA 2014-2019
}

\author{
LAERTA KAKARIQI ${ }^{1}$, SOKRAT XHAXHO ${ }^{2}$, LEONARD DEDA ${ }^{1}$, GENTIAN VYSHKA ${ }^{1 *}$
}

${ }^{1}$ Department of Biomedical and Experimental, Section of Pharmacology, Faculty of Medicine, University of Medicine in Tirana, Tirana, Albania. ${ }^{2}$ Department of Neurology, University Hospital Centre “Mother Theresa," Tirana, Albania. Email: gvyshka@gmail.com

Received: 28 August 2021, Revised and Accepted: 04 October 2021

ABSTRACT

Objective: The aim of this paper is to evaluate 6-year trends in community use of prescribed opioid analgesics in Albania, using the Anatomic Therapeutic Chemical Classification-Defined Daily Dose methodology.

Methods: We collected the data from the database of the Health Insurance Institute (HII). Analysis of the data includes the period 2014-2019; also, we analyzed the data of import and domestic production of drugs, which represent the real consumption of drugs in the country. These data were subsequently involved in a comparative analysis of the utilization data according to the HII.

Results: We report a 2.5 fold increase in opioid utilization over the study period. The maximal rise in consumption refers to fentanyl, oxycodone, and tramadol. Meanwhile, the maximal values of consumption refer to strong opiate, morphine. We note that around $30 \%$ of the consumption of this class flows out of the scheme. Furthermore, around $25 \%$ of consumption of morphine and oxycodone flows out of scheme too. Meanwhile, the tramadol consumption runs out of the scheme over $200 \%$.

Conclusions: The outcomes indicate that patients in Albania have low access to opioids medications mainly because of low opioids availability. A strong opiophobia among the population and the medical professionals constitutes one of the major impediments for efficient palliative care.

Keywords: Opioids, Morphine, Consumption, Defined daily dose.

(C) 2021 The Authors. Published by Innovare Academic Sciences Pvt Ltd. This is an open access article under the CC BY license (http://creativecommons.org/ licenses/by/4.0/) DOI: http://dx.doi.org/10.22159/ajpcr.2021v14i11.42688. Journal homepage: https://innovareacademics.in/journals/index.php/ajpcr

\section{INTRODUCTION}

Opioids are a class of drugs naturally found in the opium poppy plant and that work in the brain to produce a variety of effects, including the relief of pain with many of these drugs. Some prescription opioids are a direct product of the plant. Other opioids are synthetized in labs, by using the same chemical structure. Opioids often are used as medicines because they contain chemicals that relax the body and can relieve pain. Opioids can also make people feel very relaxed and "high" - which is why they are sometimes abused even for non-medical reasons. This can be dangerous because opioids can be highly addictive, and overdoses and death are common.

The prevalence of chronic pain is high and affects $12-30 \%$ of all Europeans, with a considerable impact on self-reported quality of life, posing a major international healthcare issue [1]. For some patients, opioids are used to treat chronic pain, and the total use of opioids more than doubled from 1999 to 2016 worldwide [2].

Prescription opioids might be used to treat moderate-to-severe pain. Often these are prescribed following surgery or injury, or for health conditions such as cancer. In recent years, there has been a dramatic increase in the acceptance and use of prescription opioids for the treatment of chronic non-cancer pain (CNCP), such as back pain or osteoarthritis, despite serious risks and the lack of evidence about their long-term effectiveness. Studies suggest that regional variation in use of prescription opioids cannot be explained by the underlying health status of the population [3]. More than 191 million opioid prescriptions were dispensed to American patients in 2017 - with wide variation across states [4]. Anyone who takes prescription opioids can become addicted to them. In fact, as many as one in four patients receiving long-term opioid therapy in a primary care setting struggles with opioid addiction [5-7]. Once addicted, it can be hard to stop. In 2016, more than 11.5 million Americans reported misusing prescription opioids in the past year [4]. Taking too many prescription opioids could stop a person's breathing - leading to death.
In USA, Opioid prescriptions per capita increased 7.3\% from 2007 to 2012, with opioid prescribing rates increasing more for family practice, general practice, and internal medicine compared with other specialties [8]. Opioids are commonly prescribed for pain. An estimated $20 \%$ of patients presenting to physician offices with non-cancer pain symptoms or pain-related diagnoses (including acute and chronic pain) receive an opioid prescription [9].

\section{METHODS}

The study aimed to assess the out-of-hospital Opioid drugs use in Albania during the period 2014-2019. The data were obtained from the Health Insurance Institute (HII) [10]. All data were collected for the period 2014-2019 and analyzed. The analysis included the total number of prescriptions made and quantities of drugs used.

The data about the population were obtained from the Institute of Statistics [11]. The data about the consumption of drugs were expressed as a number of Defined Daily Dose (DDDs)/1000 inhabitants/day. All drugs were classified by groups of Anatomic Therapeutic Chemical Classification (ATC)

\section{Data on real consumption (import and domestic production)}

For all the period under study 2014-2019, there were collected and analyzed data from the import and domestic production of the drugs, which represent the real consumption of drugs in the country [12]. To obtain an updated study, there were chosen the data of import and domestic consumption only for the last 4 years, 2016, 2017, 2018, and 2019 and those were involved in a comparative analysis with the equivalent consumption data according to HII. To minimize the effect of variations between consumption and stock inventory balances from 1 year to another, it was calculated and put to analysis the annual average value of the three chosen years (on the one hand, that of the import and domestic consumption, and, on the other hand, that of HII). 
Presentation of the results and statistical elaboration

The database of HII was modified in Microsoft Office Excel 2007, whereas the statistical elaboration of the obtained results was conducted with the statistical package StatsDirect (version 2.7.2.). A descriptive statistic was used to report all data on drugs consumption and the results obtained were displayed in tabular form as well as through the histogram method.

Average annual values of consumption in the country level and for each district were used as a basis to generate the overviews and the graphics that illustrate the trends of consumption for each class of drugs during the 6-years period 2014-2019. The linear regression model was used to evaluate the trends of consumption of drugs relative to the time. A value of $\mathrm{p} \leq 0.05$ was considered as significant.

\section{RESULTS}

The data are expressed as a number of DDDs per 1000 inhabitants/day (DDDs/1000 inhabitants/day).

The consumption of opioid drugs was 2.21-5.44 DDD/1000 inhabitants/day, respectively, in 2014-2019, reflecting a specific increase of approximately $150 \%$. The opioids included in the reimbursement scheme are morphine, fentanyl, oxycodone, pethidine, and tramadol. The most prescribed are morphine and oxycodone; meanwhile, the largest increase in consumption is attributed to fentanyl and oxycodone (Figs. 1 and 2) [13-22]

\section{DISCUSSION}

Chronic pain is one of the largest contributors to global disability [23]. Prevention, assessment, and treatment of chronic pain are challenges for health providers and systems. Pain might go unrecognized, and patients, particularly members of racial and ethnic minority groups, women, the

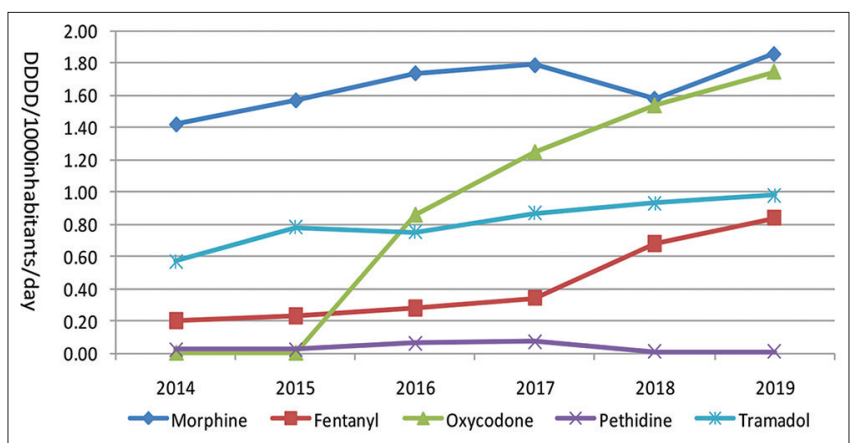

Fig. 1: Consumption of each opioid at national level (Defined Daily Dose /1000 inhabitants/day)

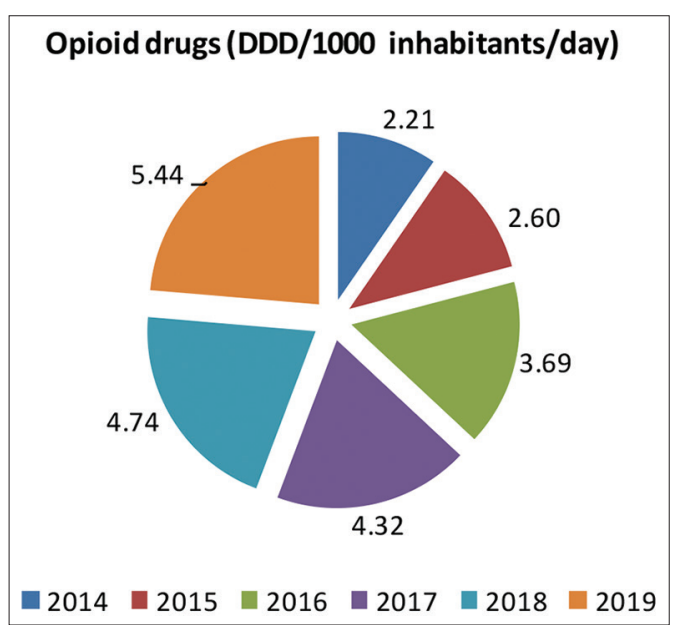

Fig. 2: Opioid consumption at national leve (Defined Daily Dose /1000 inhabitants/day) p=0.0089; strength (with significance level $\leq 0.05$ ) $=93.84 \%$; correlation coefficient statistically significant elderly, persons with cognitive impairment, and those with cancer and at the end of life, can be at risk for inadequate pain treatment [24]. Patients can experience persistent pain that is not well controlled. There are clinical, psychological, and social consequences associated with chronic pain including limitations in complex activities, lost work productivity, reduced quality of life, and stigma, emphasizing the importance of appropriate and compassionate patient care [24]. Chronic pain has been variably defined but is defined within this guideline as pain that typically lasts $>3$ months or past the time of normal tissue healing [25]. Chronic pain can be the result of an underlying medical disease or condition, injury, medical treatment, inflammation, or an unknown cause [24].

Evidence supports short-term efficacy of opioids for reducing pain and improving function in non-cancer nociceptive and neuropathic pain in randomized clinical trials lasting primarily $\leq 12$ weeks $[26,27]$, and patients receiving opioid therapy for chronic pain report some pain relief when surveyed [28-30]. However, few studies have been conducted to rigorously assess the long-term benefits of opioids for chronic pain (pain lasting >3 months) with outcomes examined at least 1 year later [31]. Opioid pain medication use presents serious risks, including overdose and opioid use disorder. In the past decade, while the death rates for the top leading causes of death such as heart disease and cancer have decreased substantially, the death rate associated with opioid pain medication has increased markedly [32]

In the past two decades, various opioids, including oxycodone, hydromorphone, buprenorphine and fentanyl, have been registered and subsidized for the treatment of CNCP in many health care settings around the globe. These changes brought dramatic growth in opioid prescribing and use, despite uncertainty about their efficacy in the long-term treatment of this indication [33,34].

This paper provides an evaluation of Albanian trends in prescribed opioid analgesic dispensing. Opioids are essential medicines for the treatment of pain and have been included in the 2007 Essential Medicines in Palliative Care by International Association for Hospice and Palliative Care. The list includes 34 medications of which 14 are already included in the WHO list as essential in the treatment of several conditions, some of which are common in palliative care from which 27 drugs or $75 \%$ are available in Albania. In the reimbursement drug list of Fund of Health Care Insurance, 17 drugs are included or $48 \%$. Meanwhile, $20 \%$ of this group of drugs (reimbursed for palliative care) has limitations on their use and quantity [35].

We report a 2.5 fold increase in opioid utilization over the study period. The maximal rise in consumption refers to fentanyl, oxycodone, and tramadol. Meanwhile the maximal values of consumption refers to strong opiate (morphine), Figs. 1-3 show clearly that consumption of opioids have an increasing trend, especially from 2016 onward.

Attempting to obtain a deeper understanding of what has really happened we included in the analysis the import data (which represent the real consumption), by comparing the average annual value of consumption of opioids drugs from imports with the equivalent value reported by the HII. Fig. 4 presents the comparison import-HII in the consumption of opioids the whole class, and some representatives like morphine, tramadol, and oxycodone. We note that around $30 \%$ of the consumption of this class flows out of the scheme. Furthermore, around $25 \%$ of consumption of morphine and oxycodone flows out of scheme too. Meanwhile, the tramadol consumption runs out of the scheme over $200 \%$. The distribution of opioids in the pharmaceutical market relies in accordance to a well-determined regulation. Only a small number of pharmacies do have the right to sell opioids. These pharmacies apply for a special license with the Ministry of Health and Social Welfare. They can start selling opioids only after being equipped with such license and ensuring a separate place for opioids - a safe deposit box/cabinet. On the other hand, to have the right to purchase opioids, a patient should obtain a special medical prescription, duly signed and stamped by three doctors.

General physicians are able to prescribe opioids, but only after an oncological consultancy. The authority for prescribing opioids is limited to palliative 


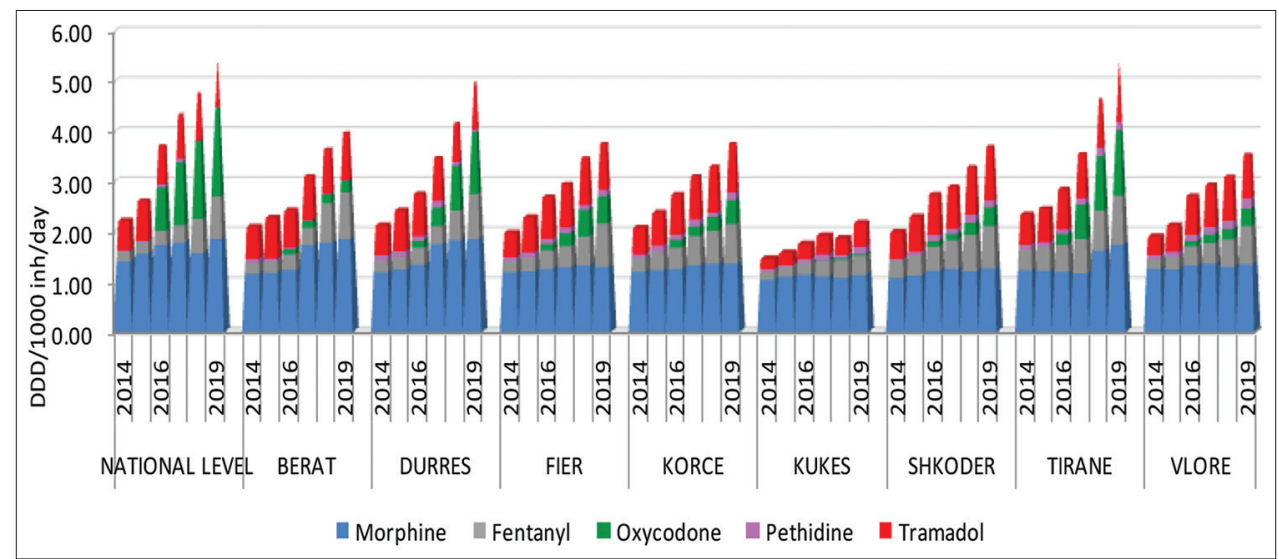

Fig. 3: Consumption of opioids in different regions and at the national level (defined daily dose/1000 inhabitants/day)

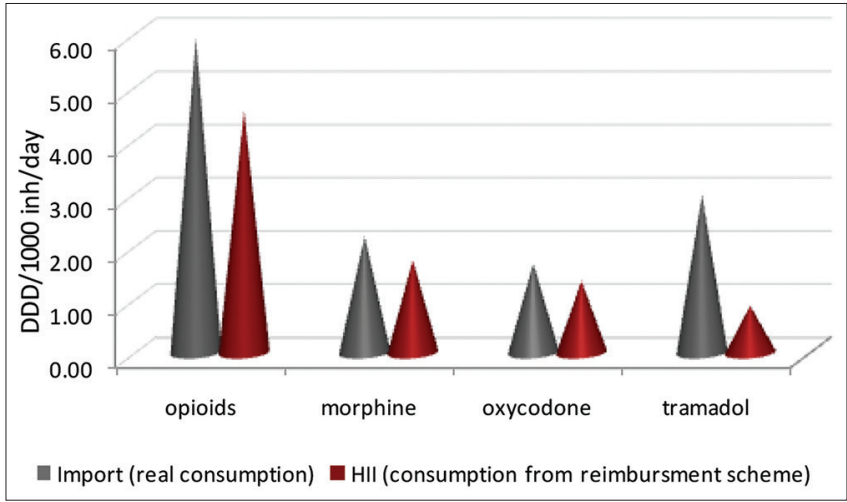

Fig. 4: Annual average value of consumption of Opioids: Consumption based on import (real consumption) $\left({ }^{*}\right)$ versus Consumption based on Health Insurance Institute. $\left({ }^{*}\right)$ The "Import" item includes the consumption based on import data as well as the consumption based on domestic production: This represents the factual consumption

care physicians and oncologists. There are four palliative care services operating in Albania. The length of a prescription has been limited to 7 days, but because of the new legal stipulations, it was expanded to a maximum of 28 days [35]. For many years the only opiate available, was morphine $10 \mathrm{mg}$ injection and $10 \mathrm{mg}$ slow-release tablet. In 2014, patch fentanyl was also included in the scheme. Whereas, in 2016, the scheme extended further by including morphine oral solution (oral drops) and oxycodone $10 \mathrm{mg}$ tablet.

In Albania, prescription opioids are used almost entirely to treat cancer associated moderate-to-severe pain. They are prescribed in isolated cases also by an orthopedist or endocrinologist for the treatment of diabetic foot ulcer, or for pains from multiple fractures. On the contrary, in European countries opioids are commonly prescribed for pain. An estimated $20 \%$ of patients presenting to physician offices with non-cancer pain symptoms or pain-related diagnoses (including acute and chronic pain) receive an opioid prescription [9].

One reason for this prescription disparity is ophidiophobia, a closed mentality amongst the medical staff and throughout the population. Another possible reason may be their significantly high price in our country as compared to in other European countries. When comparing the scheme data with the customs import figures, where the latter indicate the real consumption in the country, we note that around $30 \%$ of opioids flow out of the scheme. We need to consider here that the customs import figures include also the hospital consumption of opioids. When analyzing item by item, we note consumption values out of the scheme at the level of $26 \%$ for morphine and $25 \%$ for oxycodone. An explanation for this finding may be the informal trading of these drugs (under the counter), or alternatively, their residual stock inventory may be an explanation. Between the two of them, oxycodone is more easily accessible.

Meanwhile, when we compare consumption values for tramadol, we note that the real consumption exceeds by far the consumption under the scheme, by around 3.4 times. Probable reasons are the fact that tramadol is available in all pharmacies, can be obtained through a simple prescription issued by only one doctor and its cost is much low. In fact it represents the only alternative in the opioids group that is prescribed extensively also in non-cancer chronical pains.

The consumption of opioids undergoes an increasing trend more conspicuous from 2016 onwards (this year oxycodone and oral drops morphine solution were introduced to the reimbursement list). Minimum consumption is noted in Kukës throughout all years under study. High values of consumption for this class are noted in Tiranë and Durres. The first palliative care service provider in Albania, the Ryder Albanian Association (RAA) from 1993, operate precisely in Tirana and Durres. RAA's focus is the provision of home care, palliative care, advocacy, and fundraising [35].

Worth mentioning is though that from 2015, in addition to the four nongovernment organizations providing palliative care, there are seven new palliative care units in the regional hospitals of Albania: In Shkodra, Elbasan, Durrës, Fieri, Berat, Korça, Kukësi, and Vlora offering inpatient and home care services for patients [35].

\section{Comparisons of consumption at the international level}

Opioids have become the cornerstone therapy for treatment of moderate to severe pain in many high-income countries. For prescription opioids, while there is insufficient access in many low- and middle-income countries, the reality in OECD countries is quite different, where the availability of analgesic opioids has been steadily growing. The United States has the highest availability of analgesic opioids among OECD countries, followed by Germany and Canada, while Mexico, Chile, and Colombia show the lowest numbers [36].

In 2019, we report dispensing of opioid analgesics at a rate of 5.44 DDD/1000 inhabitants/day; this is much lower than rates in Canada (22 DDD/1000 inh/day in 2010) and Scandinavia (approximately 20 DDD/1000 inh/day in 2006), who are among the leading consumers of opioid analgesics globally. However, the use of opioids in the treatment of CNCP is controversial $[37,38]$. While randomized-controlled trials have demonstrated efficacy of opioids for the short-term treatment of chronic pain [39-41], there is no high-quality evidence for their long-term efficacy [42-44]. Other contributors to the increase in opioid utilization may include the ageing population; improvements in pain management and physician education; recognition of the serious side effects of NSAIDs and Cox-2 inhibitors; and growth in opioid misuse and diversion [45-49]. In Fig. 5, we may again conclude that in Albania, these drugs are consumed a few times less as compared to the majority of other countries, leaving room 


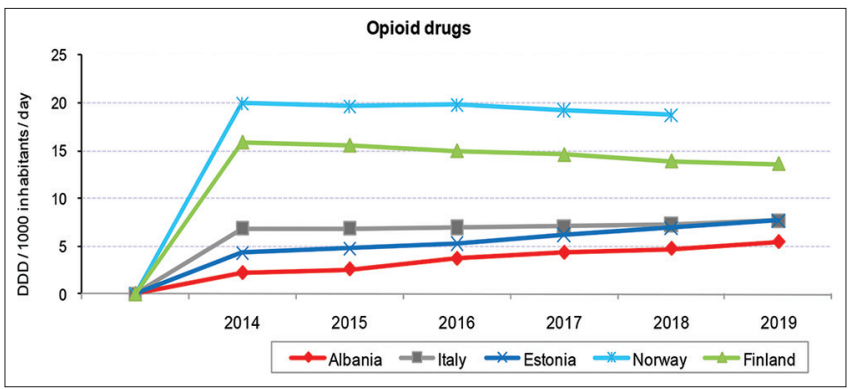

Fig. 5: International comparison in the consumption of opioid drugs class (defined daily dose/1000 inhabitants/day): Albania, Italy [13], Estonia [14], Norway [15-18], Finland [19-22]

to assume that there is under-treatment of pain disorder, and under provision of palliative care services throughout the country.

\section{CONCLUSIONS}

The outcomes indicate that patients in Albania have low access to opioids medication, mainly because of low opioids availability. A strong opiophobia among the population and the medical professionals constitutes one of the major impediments for efficient palliative care. To remove this barrier to the treatment of pain, there is a need for a better awareness and education of clinicians, so to avoid exaggerated fear from side effects or addiction, while using this highly efficacious pain-relieving type of medication.

\section{AUTHORS' CONTRIBUTIONS}

LK wrote the introduction; LK and GV wrote the methodology and results; LK, SX and LD wrote the discussion section. All authors reviewed the references and approved the final version.

\section{CONFLICT OF INTEREST}

Nothing to declare.

\section{FUNDING}

No funding received for the present paper.

\section{REFERENCES}

1. Breivik H, Collett B, Ventafridda V, Cohen R, Gallacher D. Survey of chronic pain in Europe: Prevalence, impact on daily life, and treatment. Eur J Pain 2006;10:287-333.

2. International Narcotics Control Board. Estimated World Opioid Requirements for 2018; 2018. Vienna: United Nations Publication. Available from: https://www.incb.org/incb/en/narcotic-drygs/Technical Reports/narcotic drugs reports.html [Last accessed on 2018 Feb 10]

3. Paulozzi LJ, Mack KA, Hockenberry JM. Vital signs: Variation among states in prescribing of opioid pain relievers and benzodiazepines United States, 2012. MMWR Morb Mortal Wkly Rep 2014;63;563-8.

4. Centers for Disease Control and Prevention. 2018 Annual Surveillance Report of Drug-Related Risks and Outcomes United States. Surveillance Special Report 2pdf icon. Centers for Disease Control and Prevention, U.S. Department of Health and Human Services. Published August 31; 2018.

5. Banta-Green CJ, Merrill JO, Doyle SR, Boudreau DM, Calsyn DA. Opioid use behaviors, mental health and pain development of a typology of chronic pain patients. Drug Alcohol Depend 2009;104:34-42.

6. Boscarino JA, Rukstalis M, Hoffman SN, Han JJ, Erlich PM, Gerhard GS, et al. Risk factors for drug dependence among outpatients on opioid therapy in a large US health-care system. Addiction 2010;105:1776-82

7. Fleming MF, Balousek SL, Klessig CL, Mundt MP, Brown DD. Substance use disorders in a primary care sample receiving daily opioid therapy. J Pain 2007;8:573-82

8. Levy B, Paulozzi L, Mack KA, Jones CM. Trends in opioid analgesic prescribing rates by specialty, U.S., 2007-2012. Am J Prev Med 2015;49:409-13.
9. Daubresse M, Chang HY, Yu Y, Viswanathan S, Shah ND, Stafford RS, et al. Ambulatory diagnosis and treatment of nonmalignant pain in the United States, 2000-2010. Med Care 2013;51:870-8.

10. Health Insurance Institute, Tirana, Albania. Available from: http://www. fsdksh.com.al/images/2017/Botime/Raporti_Vjetor_2016/Raporti_ Vjetor_FSDKSH_Anglisht.pdf [Last accessed on 2021 Mar 03].

11. Institute of Statistics; INSTAT, Tirana, Albania. Available from: http:// www.instat.gov.al/en [Last accessed on 2021 Mar 03]

12. General Customs Directorate, Ministry of Finance, Tirana, Albania. Available from: http://www.dogana.gov.al/english/c/171/197/199/ general-directorate-of-customs [Last accessed 2021 on Mar 03].

13. Rapporti OsMed Agenzia Italiana del Farmaco. Available from: https://aifa.gov.it> rapporti-osmed. L'uso dei farmaci in Italia FNOPI; (2009-2019); 2021

14. Statistics on Medicines Ravimiamet. Available from: https:// ravimiamet.ee > statistics-medicines. Available from: http://www. ravimiamet.ee/en/statistics-medicines; $\quad \mathrm{http}: / / \mathrm{www} \cdot$ ravimiamet. ee>baltijas_statistika_2016-2018 [Last accessed on 2021 Mar 03].

15. Norwegian Institute of Public Health. Drug Consumption in Norway 2006-2010. Department of Pharmaco-epidemiology, Norwegian Institute of Public Health. Available from: http://www. legemiddelforbruk.no [Last accessed on 2021 Mar 03].

16. Drug Consumption in Norway 2011-2015. Available from: https://www.fhi.no/globalassets/dokumenterfiler/rapporter/2016/ legemiddelforbruket-i-norge-2011-2015-pdf.pdf [Last accessed on 2021 Mar 03]

17. Drug Consumption in Norway 2011-2015. Available from: https://www. fhi.no/en/publ/2017/drug-consumption-2012-2016 [Last accessed on 2021 Mar 03]

18. Suomen lääketilasto 2019, Finnish Statistics on Medicines. Suomen lääketilasto; 2019.

19. Finnish Statistics on Medicines 2007. National Agency for Medicines, Department of Safety and Drug Information. Available from: https:// www.kela.fi/web/en/statistical-publications finnish-statistics-onmedicines [Last accessed on 2021 Mar 03].

20. Finnish Statistics on Medicines 2014. National Agency for Medicines, Department of Safety and Drug Information. Available from: https:// www.kela.fi/web/en/statistical-publications_finnish-statistics-onmedicines [Last accessed on $2021 \mathrm{Mar}$ 03].

21. Finnish Statistics on Medicines 2016. National Agency for Medicines, Department of Safety and Drug Information. Available from: https:// www.kela.fi/web/en/statistical-publications finnish-statistics-onmedicines [Last accessed on 2021 Mar 03].

22. 2019: Legemiddelforbruket i Norge 2014-2018. elektronisk utgave: 978-82-8406-011-8 [Last accessed on 2021 Mar 03].

23. Vos T, Flaxman AD, Naghavi M, Lozano R, Michaud C, Ezzati M, et al. Years lived with disability (YLDs) for 1160 sequelae of 289 diseases and injuries 1990-2010: A systematic analysis for the Global burden of disease study 2010. Lancet 2013;380:2163-96.

24. Institute of Medicine. Relieving pain in America: A Blueprint for Transforming Prevention, Care, Education, and Research. Washington, DC: The National Academies Press; 2011.

25. International Association for the Study of Pain. Classification of chronic pain. Descriptions of chronic pain syndromes and definitions of pain terms. Prepared by the international association for the study of pain, subcommittee on taxonomy. Pain Suppl 1986;3:S1-226.

26. Furlan A, Chaparro LE, Irvin E, Mailis-Gagnon A. A comparison between enriched and nonenriched enrollment randomized withdrawal trials of opioids for chronic non-cancer pain. Pain Res Manag 2011;16:337-51

27. American Pain Society, American Academy of Pain Medicine Opioids Guidelines Panel. Guideline for the use of chronic opioid therapy in chronic non-cancer pain: Evidence review. Chicago, IL: American Pain Society; 2009. Available from: http://americanpainsociety.org/uploads/ education/guidelines/chronic-opioid-therapy-cncp.pdf

28. Anastassopoulos KP, Chow W, Tapia CI, Baik R, Moskowitz B, Kim MS. Reported side effects, bother, satisfaction, and adherence in patients taking hydrocodone for non-cancer pain. J Opioid Manag 2013:9:97-109

29. Gregorian RS Jr., Gasik A, Kwong WJ, Voeller S, Kavanagh S. Importance of side effects in opioid treatment: A trade-off analysis with patients and physicians. J Pain 2010;11:1095-108.

30. Thielke SM, Turner JA, Shortreed SM, Saunders K, Leresche L, Campbell CI, et al. Do patient-perceived pros and cons of opioids predict sustained higher-dose use? Clin J Pain 2014;30:93-101.

31. Chou R, Deyo R, Devine B, Hansen R, Sullivan S, Jarvik JG. The Effectiveness and Risks of Long-term Opioid Treatment of Chronic Pain. 
Evidence Report/Technology Assessment No. 218. AHRQ Publication No. 14-E005-EF. Rockville, MD: Agency for Healthcare Research and Quality; 2014. Available from: http://www. effectivehealthcare. ahrq.gov/ehc/products/557/1971/chronic-painopioid-treatmentreport-141007.pdf

32. Centers for Disease Control and Prevention. National Center for Health Statistics. Health, United States, 2014: With special feature on adults aged 55-64. Hyattsville, MD: US Department of Health and Human Services, CDC, National Center for Health Statistics. Atlanta, Georgia: Centers for Disease Control and Prevention; 2015.

33. Chou R, Turner JA, Devine EB, Hansen RN, Sullivan SD, Blazina I, et al. The effectiveness and risks of long-term opioid therapy for chronic pain: A systematic review for a National Institutes of Health pathway to prevention workshop. Ann Intern Med 2015;162:276-86

34. Breivik H. Opioids in chronic non-cancer pain, indications and controversies. Eur J Pain 2005;9:127-30.

35. Rama R, Çarçani V, Prifti F, Huta K, Xhixha A, Connor SR. Palliative care-Albania. J Pain Symptom Manag 2018;55:S14-8.

36. Opioid use/Health at e Glance 2019: OECD Indicators. Available from: https://www.oecd-ilibrary.org

37. Fischer B, Jones W, Rehm J. Trends and changes in prescription opioid analgesic dispensing in Canada 2005-2012: An update with a focus on recent interventions. BMC Health Serv Res 2014;14:90.

38. Hamunen K, Paakkari P, Kalso E. Trends in opioid consumption in the Nordic countries 2002-2006. Eur J Pain 2009;13:954-62.

39. US Food and Drug Administration. FDA Announces Safety Labeling Changes and Post Market Study Requirements for Extended-release and Long-acting Opioid Analgesics. Press Release; 2013. Available from:
http://www.fda.gov/NewsEvents/Newsroom/PressAnnouncements/ ucm367726.htm [Last accessed on 2015 Sep 16].

40. Furlan AD, Sandoval JA, Mailis-Gagnon A, Tunks E. Opioids for chronic noncancer pain: A meta-analysis of effectiveness and side effects. Can Med Assoc J 2006;174:1589-94.

41. Przewłocki R, Przewłocka B. Opioids in chronic pain. Eur J Pharmacol 2001;429:79-91.

42. Ballantyne JC, Shin NS. Efficacy of opioids for chronic pain: A review of the evidence. Clin J Pain 2008;24:469-78.

43. Noble M, Treadwell JR, Tregear SJ, Coates VH, Wiffen PJ, Akafomo C, et al. Long-term opioid management for chronic noncancer pain. Cochrane Database Syst Rev 2010;1:CD006605.

44. Chaparro LE, Furlan AD, Deshpande A, Mailis-Gagnon A, Atlas S, Turk DC. Opioids compared to placebo or other treatments for chronic low-back pain. Cochrane Database Syst Rev 2013;8:CD004959.

45. Campbell CI, Weisner C, LeResche L, Ray GT, Saunders K, Sullivan MD, et al. Age and gender trends in long-term opioid analgesic use for noncancer pain. Am J Public Health 2010;100:2541-7.

46. Melnikova I. Pain market. Nat Rev Drug Discov 2010;9:589-90.

47. Makris UE, Abrams RC, Gurland B, Reid MC. Management of persistent pain in the older patient: A clinical review. JAMA 2014;312:825-37.

48. Atluri S, Sudarshan G, Manchikanti L. Assessment of the trends in medical use and misuse of opioid analgesics from 2004 to 2011. Pain Physician 2014;17:e119-28.

49. Buntin-Mushock C, Phillip L, Moriyama K, Palmer PP. Age-dependent opioid escalation in chronic pain patients. Anesth Analg 2005; 100:1740-5. 